\title{
ORIGINAL
}

ARTICLES

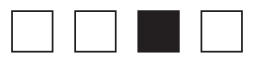

\section{Maternity Care Tracks at US Family Medicine Residency Programs}

Steven Roskos, MD; Tyler Barreto, MD; Julie Phillips, MD; Valerie J. King, MD; W. Suzanne Eidson-Ton, MD; Aimee Eden, PhD

BACKGROUND AND OBJECTIVES: The number of family physicians providing maternity care continues to decline, jeopardizing access to needed care for underserved populations. Accreditation changes in 2014 provided an opportunity to create family medicine residency maternity care tracks, providing comprehensive maternity care training only for interested residents. We examined the relationship between maternity care tracks and residents' educational experiences and postgraduate practice.

METHODS: We included questions on maternity care tracks in an omnibus survey of family medicine residency program directors (PDs). We divided respondent programs into three categories: "Track," "No Track Needed," and "No Track." We compared these program types by their characteristics, number of resident deliveries, and number of graduates practicing maternity care.

RESULTS: The survey response rate was $40 \%$. Of the responding PDs, 79 (32\%) represented Track programs, 55 (22\%) No Track Needed programs, and 94 (38\%) No Track programs. Residents in a track attended more deliveries than those not in a track (at Track programs) and those at No Track Needed and No Track programs. No Track Needed programs reported the highest proportion of graduates accepting positions providing inpatient maternity care in 2019 (21\%), followed by Track programs $(17 \%)$ and No Track programs $(5 \%$; $\mathrm{P}<.001)$.

CONCLUSIONS: Where universal robust maternity care education is not feasible, maternity care tracks are an excellent alternative to provide maternity care training and produce graduates who will practice maternity care. Programs that cannot offer adequate experience to achieve competence in inpatient maternity care may consider instituting a maternity care track.

(Fam Med. 2021;53(10):857-63.)

doi: 10.22454/FamMed.2021.237852

$\mathbf{T}$ he number of family physicians providing maternity care continues to decline in the United States. ${ }^{1,2}$ Key factors motivating this change are thought to be inability to secure a job that includes maternity care ${ }^{2,3}$; lifestyle concerns ${ }^{2}$; decreased interest by family physicians in providing maternity care $^{4}$; medical malpractice costs ${ }^{5-7}$; and lack of support from hospitals, employers, ${ }^{8,9}$ and obstetricians. ${ }^{10}$ In addition, the family medicine workforce is aging, with up to $40 \%$ of family physicians over age 55 years in some states, ${ }^{11}$ which may lead to the retirement of many family physicians who provide maternity care in the next 10 years. Continuing to train family physicians to provide maternity care is critical, as family physicians provide the majority of maternity care in US rural hospitals ${ }^{12}$ and sometimes provide all maternity care including cesarean deliveries in rural communities. ${ }^{13-15}$

Access to prenatal care and delivery services is strongly related to better maternal and infant outcomes. ${ }^{16,17}$ A broad scope of family medicine practice has also been associated with better health outcomes for patients ${ }^{18}$ and well-being of physicians. ${ }^{19}$ If the family medicine maternity care workforce continues to decline, the loss of access to maternity services in rural and economically disadvantaged communities will likely worsen health disparities and the already unacceptably high maternal mortality rate in the United States. ${ }^{15,20}$

In 2014, The Accreditation Council for Graduate Medical Education (ACGME) released updated requirements for family medicine residency training. ${ }^{21}$ These updates required significantly less experience and competence in maternity care compared to the 2007 requirements and have remained unchanged through

From Michigan State University College of Human Medicine, Department of Family Medicine, \& Sparrow Hospital Department of Family Medicine, East Lansing, MI (Drs Roskos and Phillips); Sea Mar Marysville Family Medicine Residency Program, Marysville, WA (Dr Barreto); Oregon Health and Science University, Department of Family Medicine (Dr King); University of California, Davis, Department of Family \& Community Medicine (Dr Eidson-Ton); and the American Board of Family Medicine, Lexington, KY (Dr Eden). 
the most recent revision in 2020 . One solution to the need for additional family physicians who provide maternity care in light of the changed ACGME requirements for family medicine training is the opportunity for enhanced maternity care training for interested residents. ${ }^{15,22}$

A recent Council of Academic Family Medicine Educational Research Alliance (CERA) survey of 245 program directors aimed to understand trends in family medicine resident maternity care experiences after the 2014 change in ACGME requirements. This survey found that the majority $(62 \%)$ of program directors estimate that fewer than $10 \%$ of their residents continue to attend vaginal deliveries after graduation. Only 11 program directors (4\%) estimated that more than $50 \%$ of their graduates continue to attend vaginal deliveries. ${ }^{23}$

Characteristics of family medicine residents who intend to practice maternity care include female gender, $\mathrm{MD}$ degree (vs DO), and participation in a loan repayment program. Characteristics of residencies likely to train residents who intend to practice maternity care include geographic location in the West or Midwest, more months of required maternity care rotations, presence of a maternity care fellowship, funding as a teaching health center, and lower number of beds at the primary admitting hospital, as well as strong family medicine attending presence in the provision and privileging of maternity care. ${ }^{24-26}$ The only curriculum-related factor listed is months of required maternity care rotations, in other words, increased exposure to maternity care. A maternity care track increases exposure to maternity care and may allow for greater concentration of resources on trainees likely to provide maternity care in their future practices. ${ }^{26}$ Maternity care tracks may also enable highly interested residents to develop advanced maternity care skills. The updated 2014 ACGME requirements provided an opportunity and incentive for programs to create maternity care tracks.

The purpose of our study was to examine the relationship between maternity care tracks and family medicine residents' maternity care educational experiences and graduate practice. Based on previous studies, ${ }^{15,26}$ we hypothesized that residents at programs with maternity care tracks would have more maternity care experience (as measured by the number of vaginal deliveries) and be more likely to practice maternity care after graduation than residents at programs without maternity care tracks.

\section{Methods}

We piloted a version of the survey questions (Table 1) in 2018 among the Michigan State University Family Medicine Residency Network program directors ${ }^{27}$ and demonstrated that delivery of the survey is feasible. We then included the piloted questions as part of a larger omnibus survey conducted by CERA. The methodology of the CERA Program Director Survey has previously been described in detail. ${ }^{28}$ The CERA steering committee evaluated questions for consistency with the overall subproject aim, readability, and existing evidence of reliability and validity. The survey was pretested with family medicine educators who were not part of the target population. Questions were modified following pretesting for flow, timing, and readability. The American Academy of Family Physicians Institutional Review Board approved this project in April 2020. Data were collected from May 11, 2020 to June 2, 2020.

The sampling frame for the survey was all ACGME-accredited US family medicine residency program directors, as identified by the Association of Family Medicine Residency Directors. Email invitations to participate were delivered with the survey using the online program SurveyMonkey. Two follow-up emails were sent weekly after the initial email invitation and a third reminder was sent 2 days before the survey closed.
Although there were 698 program directors at the time of the survey, three had no email address indicated and 35 had previously opted out or blocked SurveyMonkey surveys. Therefore, the survey was emailed to 660 individuals. The survey contained a qualifying question to remove programs that had not had three graduating resident classes (34 programs), reducing the eligible sample size to 626 program directors.

We divided respondents into three categories: "Track" programs, "No Track Needed" programs, and "No Track" programs. The programs of program directors (PDs) who answered "yes" to question three, "Does your program offer a maternity care track?" were classified as Track programs. The programs of PDs who answered "no" to question three and indicated that the primary or secondary barrier for developing a maternity care track was "Our graduates achieve competence to provide inpatient maternity care without a maternity care track," were classified as No Track Needed. The programs of PDs who answered no to question three but gave other reasons when asked "What is your program's greatest obstacle to starting a maternity care track?" were classified as No Track programs. In other words, the programs with no maternity care track were divided into two groups. Graduates of No Track Needed programs were able to achieve maternity care competence without a maternity care track. No Track programs' directors listed other barriers to having a maternity care track, rather than being able to achieve competence without one.

We compared demographic characteristics and responses among the groups. We examined all variables for relationships with two outcomes of interest: number of deliveries and percentage of 2019 graduates providing maternity care, as reported by the program directors. We also compared demographics of survey respondents to those of non-respondents, when available, using $\chi^{2}$ analyses. 
Table 1: Maternity Track Survey Questions

1. How many residents graduated from your program in 2019 ?

2. Among the residents who graduated from your program in 2019 , how many accepted positions providing inpatient maternity care?

3. Does your program offer a maternity care track for residents with a special interest in providing inpatient maternity care after graduation?

For those who answered "no," to Question 3 these five questions followed:

1. Do you have plans to start a maternity care track? (yes/no)

2. What is your program's greatest obstacle to starting a maternity care track?

a. Our graduates achieve competence to provide inpatient maternity care without a maternity care track.

b. Residents are not interested in maternity care.

c. Family medicine faculty are not interested in maternity care.

d. The obstetrics department is not supportive of family medicine maternity care training.

e. Hospital administration is not supportive of family medicine maternity care training.

f. Volume of pregnant patients would not support a maternity care track.

g. Hospital does not provide inpatient maternity care.

3. What is your program's second greatest obstacle to starting a maternity care track? (same choices as above)

4. At your program, how many continuity vaginal deliveries does an average resident conduct during their residency? (number field)

5. At your program, how many total vaginal deliveries does an average resident conduct during their residency? (number field)

For those who answered "yes" to Question 3, these four questions followed:

1. At your program, how many continuity deliveries does an average maternity care track resident conduct during their residency?

2. At your program, how many total vaginal deliveries does an average maternity care track resident conduct during their residency?

3. At your program, how many continuity deliveries does an average resident not in a maternity care track conduct during their residency?

4. At your program, how many total vaginal deliveries does an average resident not in a maternity care track conduct during their residency?

We used univariate statistics to describe the survey results. We used bivariate statistics to examine relationships between the number of births attended by residents, presence of maternity care tracks, and graduates choosing to provide maternity care. We used $\chi^{2}$ tests and Student $t$ test to evaluate bivariate relationships, using $P<.05$ to determine statistical significance. Finally, we used hierarchical regression analyses to compare Track and No Track programs for the outcomes of interest, after controlling for other predictive variables, including known program director and program characteristics. We excluded No Track
Needed programs from the regression analyses.

\section{Results}

Of the eligible respondents, 247 program directors returned usable surveys ( $40 \%$ response rate). Nineteen of these respondents did not answer any of the maternity care track questions. Of the 228 who did, there were 79 (32\%) Track PDs, 55 (22\%) No Track Needed PDs, and 94 (37\%) No Track PDs (Table 2). There were significant differences by region, with the largest proportion of No Track Needed programs in the West and Midwest regions and the largest number of Track programs in the South region $(P=.002)$. Track programs and No Track Needed programs were more likely to be larger, and few programs in small communities had tracks $(P<.05$, Table 2$)$. No Track programs were less likely to have directors with $\mathrm{DO}$ degrees $(P=.006)$. Survey respondents did not significantly differ from nonrespondents in geographic region. However, MDs (vs DOs) were slightly overrepresented among survey respondents ( $80.2 \%$ of respondents vs $72.2 \%$ of nonrespondents, $P=.028$ ).

Within the 79 Track programs, graduating residents participating in the track were reported to have had more total deliveries (76, Table 3 ) than those not in the track (38, $P<.001)$. Both graduates in a Track 
Table 2: Demographic Characteristics of Three Types of Residency Programs

\begin{tabular}{|c|c|c|c|c|}
\hline & Track, n (\%) & $\begin{array}{c}\text { No Track } \\
\text { Needed, } n \text { (\%) }\end{array}$ & No Track, $\mathrm{n}(\%)$ & P Value \\
\hline Total Programs & $79(32)$ & $55(22)$ & $94(38)$ & \\
\hline Region & & & & .002 \\
\hline West & $17(22)$ & $18(33)$ & $12(13)$ & \\
\hline Midwest & $16(20)$ & $17(31)$ & $20(21)$ & \\
\hline South & $37(47)$ & $13(24)$ & $36(38)$ & \\
\hline Northeast & $9(11)$ & $7(13)$ & $26(28)$ & \\
\hline Program Type & & & & .297 \\
\hline University based & $14(18)$ & $12(13)$ & $8(15)$ & \\
\hline Community based, university affiliated & $47(59)$ & $53(56)$ & $35(63)$ & \\
\hline Community based, nonaffiliated & $13(16)$ & $27(29)$ & $9(16)$ & \\
\hline Military & $3(4)$ & $0(0)$ & $2(4)$ & \\
\hline Other & $2(3)$ & $2(2)$ & $2(4)$ & \\
\hline Community Size & & & & .008 \\
\hline Less than 30,000 & $3(4)$ & $6(11)$ & $14(15)$ & \\
\hline 30,000 to 149,000 & $32(41)$ & $16(29)$ & $44(47)$ & \\
\hline 150,000 to 499,999 & $22(28)$ & $22(40)$ & $15(16)$ & \\
\hline More than 500,000 & $22(28)$ & $11(20)$ & $21(22)$ & \\
\hline Total Residents in 2019 & & & & .005 \\
\hline$<19$ & $22(28)$ & $15(27)$ & $46(49)$ & \\
\hline $19-31$ & $40(51)$ & $28(51)$ & $40(43)$ & \\
\hline$>31$ & $15(22)$ & $12(22)$ & $7(8)$ & \\
\hline Percent of Residents Who Are US Graduates & & & & .068 \\
\hline $0 \%-24 \%$ & $59(75)$ & $49(52)$ & $39(68)$ & \\
\hline $25 \%-49 \%$ & $8(10)$ & $14(15)$ & $6(11)$ & \\
\hline $50 \%-74 \%$ & $9(11)$ & $17(18)$ & $7(12)$ & \\
\hline $75 \%-100 \%$ & $3(4)$ & $14(15)$ & $5(9)$ & \\
\hline Program Director Degree - MD (vs D0) & $69(88)$ & $47(85)$ & $66(70)$ & .006 \\
\hline Median years in current program director position (range) & $5(.1$ to 48$)$ & $4(0$ to 29$)$ & $4.5(.3$ to 32$)$ & .591 \\
\hline Median PD years in any program director position (range) & $6(0$ to 48$)$ & $5(0$ to 29$)$ & $6(.3$ to 32$)$ & .629 \\
\hline Program Director Gender & & & & .308 \\
\hline Female & $32(41)$ & $31(56)$ & $39(42)$ & \\
\hline Male & $46(58)$ & $24(44)$ & $52(57)$ & \\
\hline Other & $1(1)$ & $0(0)$ & $1(1)$ & \\
\hline Program Director Race & & & & .569 \\
\hline American Indian or Alaska Native & $0(0)$ & $3(5)$ & $2(2)$ & \\
\hline Asian & $3(4)$ & $1(2)$ & $6(6)$ & \\
\hline Black or African American & $3(4)$ & $4(7)$ & $5(5)$ & \\
\hline Native Hawaiian or Pacific Islander & $0(0)$ & $0(0)$ & $1(1)$ & \\
\hline White & $71(90)$ & $45(82)$ & $76(82)$ & \\
\hline Choose not to disclose & $2(3)$ & $2(4)$ & $3(3)$ & \\
\hline Program Director Ethnicity & & & & .672 \\
\hline Hispanic/Latino & $5(6)$ & $4(8)$ & $4(4)$ & \\
\hline Non-Hispanic/Latino & $72(94)$ & $48(92)$ & $87(96)$ & \\
\hline
\end{tabular}


Table 3: Comparison of Maternity Care Characteristics of Three Types of Residency Programs

\begin{tabular}{|c|c|c|c|c|c|}
\hline & \multicolumn{2}{|c|}{ Track $(n=79)$} & \multirow{2}{*}{$\begin{array}{l}\text { No Track Needed } \\
\qquad(n=55)\end{array}$} & \multirow{2}{*}{$\begin{array}{c}\text { No Track } \\
(n=94)\end{array}$} & \multirow[b]{2}{*}{$P$ Value } \\
\hline & $\begin{array}{l}\text { Residents in } \\
\text { the Track }\end{array}$ & $\begin{array}{l}\text { Residents NOT } \\
\text { in the Track }\end{array}$ & & & \\
\hline Average deliveries by graduation & $\begin{array}{c}76 \text { (SD 29; range } \\
30-160)\end{array}$ & $\begin{array}{l}38(\mathrm{SD} 19 ; \\
\text { range } 3-116)\end{array}$ & $\begin{array}{c}62 \text { (SD 28; range } \\
10-146)\end{array}$ & $\begin{array}{l}26(\mathrm{SD} 15 ; \\
\text { range } 0-75)\end{array}$ & $<.001$ \\
\hline $\begin{array}{l}\text { Average continuity deliveries by } \\
\text { graduation }\end{array}$ & $\begin{array}{c}18 \text { (SD 17; range } \\
1-130)\end{array}$ & $\begin{array}{l}8 \text { (SD 8; range } \\
1-60)\end{array}$ & $\begin{array}{l}10 \text { (SD 5; range } \\
0-20)\end{array}$ & $\begin{array}{l}7 \text { (SD 7; range } \\
0-40)\end{array}$ & $<.001$ \\
\hline $\begin{array}{l}\text { Percent of graduates accepting positions } \\
\text { including inpatient maternity care }\end{array}$ & \multicolumn{2}{|c|}{17 (SD 20; range 0-100) } & $\begin{array}{c}21 \text { (SD 22; range } \\
0-85.7 \text { ) }\end{array}$ & $\begin{array}{l}5(\mathrm{SD} 10 \\
\text { range } 0-50)\end{array}$ & $<.001$ \\
\hline $\begin{array}{l}\text { Number of programs sharing hospital } \\
\text { with Ob-Gyn Residency (\%) }\end{array}$ & \multicolumn{2}{|c|}{$32(41)$} & $14(25)$ & $38(40)$ & .125 \\
\hline $\begin{array}{l}\text { Percent of family medicine faculty who } \\
\text { provide maternity care }\end{array}$ & \multicolumn{2}{|c|}{35 (SD 29) } & $51(\mathrm{SD} 30)$ & $16(\mathrm{SD} 22)$ & $<.001$ \\
\hline
\end{tabular}

and graduates of No Track Needed programs completed residency with more reported vaginal deliveries than graduates of No Track programs $(76,62$, and 26 , respectively, $P<.001)$. The average numbers of continuity deliveries for each type of program followed the same pattern; residents in a track had the most (18), followed by No Track Needed (10) programs, and then by No Track (7) programs.

In regression analysis, graduates participating in tracks completed more deliveries than graduates of No Track programs, even after controlling for other predictive variables (percentage of non-US graduates, $\mathrm{PD}$ time in role and years serving as PD, number of residents in 2019, and proportion of faculty providing maternity care; $r^{2}$ change $=0.201$, $P<.001)$. Directors of No Track Needed programs reported the highest proportion of graduates accepting positions providing inpatient maternity care in the class of 2019 (21\%), followed by directors of Track programs (17\%) and directors of No Track programs $(5 \%, P<.001)$. In regression analysis, Track program graduates were more likely to accept maternity care positions than No Track graduates, after controlling for other predictive variables (percentage of non-US graduates, number of residents in 2019, proportion of faculty providing maternity care, region, and program director race). However, the effect was small ( $r^{2}$ change $=0.031$, $P=.048$ ).

The highest percentage of faculty providing maternity care was associated with No Track Needed programs (51\%), followed by Track programs $(35 \%)$ and No Track programs $(16 \%, P<.001)$.

Of all programs that do not have a track, including both No Track and No Track Needed programs $(\mathrm{n}=149)$, the most common barrier reported was that their graduates achieve competence to provide inpatient maternity care without a track (ie, they are No Track Needed). Other common barriers to development of a maternity care track included residents not being interested in maternity care, unsupportive obstetric departments, and inadequate volume of pregnant patients (Figure 1.)

\section{Discussion}

Of all respondents to this survey of US family medicine residency program directors, only $22 \%$ indicated that their "graduates achieve competence to provide inpatient maternity care without a maternity care track." About one-third (32\%) of all respondents employed a maternity care track to provide maternity care education for a portion of their graduates. Residents graduating from a No Track Needed program were more likely to accept a position providing inpatient maternity care after graduation than graduates of a No Track program, suggesting that promoting robust maternity care education for all residents may be ideal and a maternity care track is not required to promote future practice in some residencies. However, graduates of a residency program with a maternity care track were much more likely than graduates of a No Track program, and only slightly less likely than graduates of a No Track Needed program, to accept a position providing inpatient maternity care.

Graduates of maternity care tracks also perform more total deliveries and more continuity deliveries (ie, have more maternity care experience), compared to graduates of any of the other types of programs (No Track Needed or No Track). Their delivery numbers, as reported by program directors, are in the range recommended for training in comprehensive maternity care. ${ }^{29}$ This suggests that where universal robust maternity care education is not feasible, maternity care tracks are an excellent alternative to increase the percentage of graduates who practice maternity care.

The maternity care track model may be one method to increase the maternity care physician workforce and increase access to quality maternity care. Programs that cannot offer adequate experience to achieve inpatient maternity care competence should consider instituting a maternity care track.

Findings from this study may have important policy implications 
Figure 1: Barriers to Development of Maternity Care Tracks, as Reported by Family Medicine Residency Program Directors

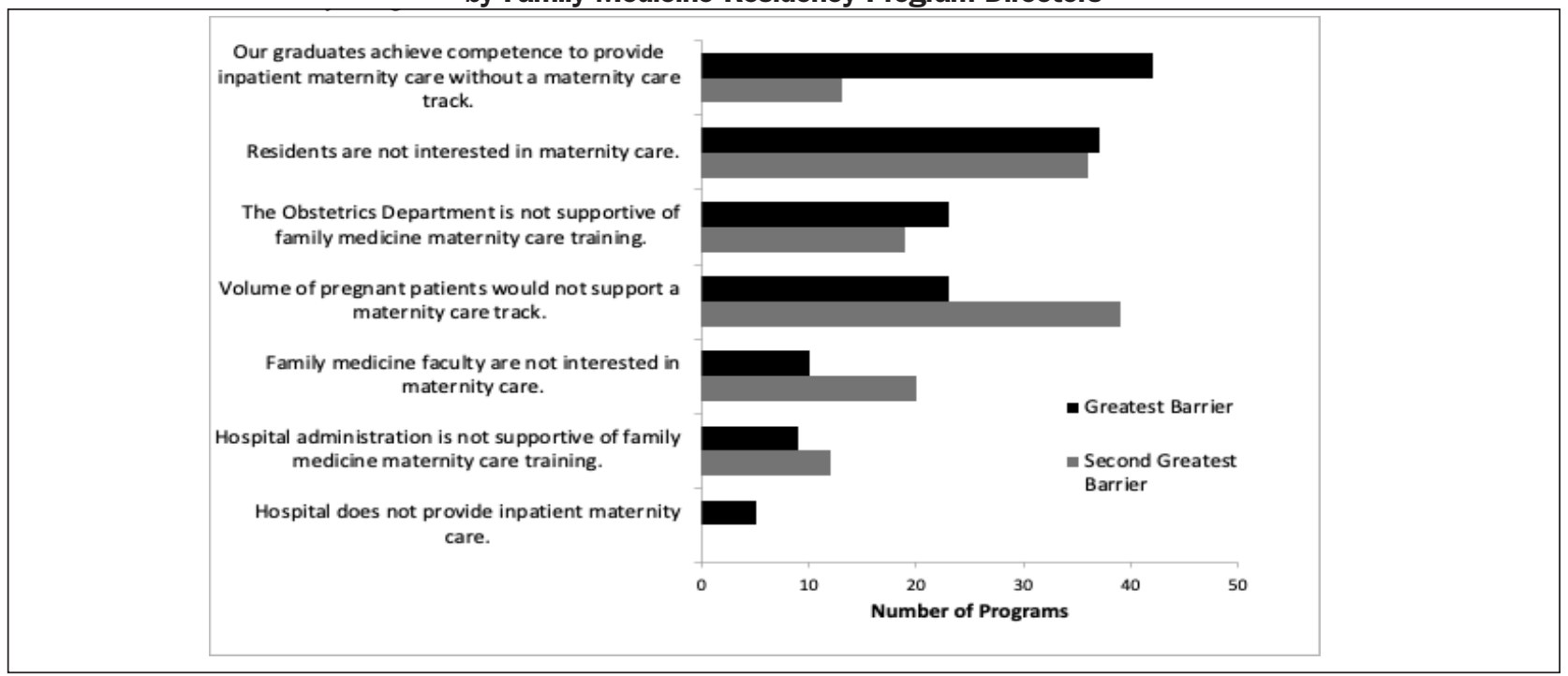

for family medicine residency education in the United States. If residency accreditation required either demonstration of adequate maternity care volume for all residents, or establishing a maternity care track for interested residents, it is possible that more family physician graduates would be qualified to perform inpatient maternity care. To achieve optimal maternity care education for family medicine residents and to appropriately evaluate such education, the essential curricular requirements, clinical experiences, and competencies for maternity care tracks should be defined.

This study is the first to systematically evaluate the maternity care track model in family medicine residencies. Limitations of this study include the use of a survey method. Although the response rate is adequate $(40 \%)$ and a higher response rate would be unlikely to reduce nonresponse bias, ${ }^{30}$ the majority of program directors did not respond. However, nonrespondents were comparable to respondents in geographic distribution. A second weakness is that program directors may not have had accurate information available to them about the questions asked or may have recalled the information incorrectly. Ideally, the actual clinical experiences of residents and the actual practices of graduates would be measured. Although we have demonstrated an association, causality should not be inferred; it is possible that residents interested in maternity care self-select for either Track or No Track Needed programs. Finally, due to the constricted length of the CERA survey, we did not query directors of programs with tracks about postgraduation practices of residents participating in the track, compared to those residents not in a track.

Despite these limitations, our findings support the usefulness of maternity care tracks for programs that cannot provide robust maternity care education for all residents. We hope that findings from this study will encourage programs in which not all residents achieve competence to perform inpatient maternity care to consider development of maternity care tracks, and that future research will aid in the development of robust educational experiences to promote a well-prepared workforce.

PRESENTATIONS: The content of this project was presented at the STFM Annual Spring Conference (virtual) in May 2021.
CORRESPONDING AUTHOR: Address correspondence to Dr Steven Roskos, Michigan State University College of Human Medicine, Department of Family Medicine, B-104A Clinical Center, 788 Service Road, East Lansing, MI 48824. 517-884-0437. Fax: 517-355-7700. roskos@msu.edu.

\section{References}

1. Barreto T, Peterson LE, Petterson S, Bazemore AW. Family Physicians Practicing High-Volume Obstetric Care Have Recently Dropped by OneHalf. Am Fam Physician. 2017;95(12):762.

2. Barreto TW, Eden A, Hansen ER, Peterson LE. Opportunities and Barriers for Family Physician Contribution to the Maternity Care Workforce. Fam Med. 2019;51(5):383-388. doi:10.22454/FamMed.2019.845581

3. Eden AR, Barreto T, Hansen ER. Experiences of new family physicians finding jobs with obstetrical care in the USA. Fam Med Community Health. 2019;7(3):e000063. doi:10.1136/ fmch-2018-000063

4. Cohen D, Coco A. Declining trends in the provision of prenatal care visits by family physicians. Ann Fam Med. 2009;7(2):128-133. doi:10.1370/afm.916

5. Benedetti TJ, Baldwin LM, Skillman SM, et al. Professional liability issues and practice patterns of obstetric providers in Washington State. Obstet Gynecol. 2006;107(6):1238-1246. doi:10.1097/01.AOG.0000218721.83011.7a

6. Xu X, Siefert KA, Jacobson PD, Lori JR, Ransom SB. The effects of medical liability on obstetric care supply in Michigan. Am J Obstet Gynecol. 2008;198(2):205.e1-205.e9. doi:10.1016/j.ajog.2007.08.043 
7. Smits AK, King VJ, Rdesinski RE, Dodson LG, Saultz JW. Change in Oregon maternity care workforce after malpractice premium subsidy implementation. Health Serv Res. 2009;44(4):1253-1270. doi:10.1111/j.14756773.2009.00984.x

8. Kozhimannil KB, Casey MM, Hung P, Han X, Prasad S, Moscovice IS. The Rural Obstetric Workforce in US Hospitals: challenges and Opportunities. J Rural Health. 2015;31(4):365372. doi:10.1111/jrh.12112

9. Hung P, Kozhimannil KB, Casey MM, Moscovice IS. Why Are Obstetric Units in Rural Hospitals Closing Their Doors? Health Serv Res. 2016;51(4):1546-1560. doi:10.1111/14756773.12441

10. Topping DB, Hueston WJ, MacGilvray P. Family physicians delivering babies: what do obstetricians think? Fam Med. 2003;35(10):737-741.

11. Wilkinson E, Bazemore E, Jabbarpour Y. Ensuring Primary Care Access in States with an Aging Family Physician Workforce. Am Fam Physician. 2019;99(12):743.

12. Young RA. Maternity Care Services Provided by Family Physicians in Rural Hospitals. J Am Board Fam Med. 2017;30(1):71-77. doi:10.3122 jabfm.2017.01.160072

13. Tong ST, Eden AR, Morgan ZJ, Bazemore AW, Peterson LE. The Essential Role of Family Physicians in Providing Cesarean Sections in Rural Communities. J Am Board Fam Med. 2021;34(1):10-11. doi:10.3122/ jabfm.2021.01.200132

14. Cullen J. Family Physicians Ability to Perform Cesarean Sections Can Reduce Maternal and Infant Mortality. J Am Board Fam Med. 2021;34(1):6-9. doi:10.3122/jabfm.2021.01.200612

15. Goldstein JT, Hartman SG, Meunier MR, et al. Supporting Family Physician Maternity Care Providers. Fam Med. 2018;50(9):662-671. doi:10.22454/FamMed.2018.325322
16. Kozhimannil KB, Hardeman RR, HenningSmith C. Maternity care access, quality, and outcomes: A systems-level perspective on research, clinical, and policy needs. Semin Perinatol. 2017;41(6):367-374. doi:10.1053/j. semperi.2017.07.005

17. Powell J, Skinner C, Lavender D, Avery D, Leeper J. Obstetric Care by Family Physicians and Infant Mortality in Rural Alabama. J Am Board Fam Med. 2018;31(4):542-549 doi:10.3122/jabfm.2018.04.170376

18. Bazemore A, Petterson S, Peterson LE, Phillips RL Jr. More Comprehensive Care Among Family Physicians is Associated with Lower Costs and Fewer Hospitalizations. Ann Fam Med. 2015;13(3):206-213. doi:10.1370/afm.1787

19. Weidner AKH, Phillips RL Jr, Fang B, Peterson LE. Burnout and Scope of Practice in New Family Physicians. Ann Fam Med. 2018;16(3):200-205. doi:10.1370/afm.2221

20. Declercq E, Zephyrin L. Maternal Mortality in the United States: A Primer. Commonwealth Fund; 2020.

21. ACGME Program Requirements for Graduate Medical Education in Family Medicine. Accreditation Council for Graduate Medical Education; 2014. Accessed October 1, 2016 2016. www.acgme.org/Specialties/Overview/ pfcatid/8/Family-Medicine

22. Young RA, Sundermeyer RL. Family medicine and obstetrics: let's stop pretending. J Am Board Fam Med. 2018;31(3):328-331. doi:10.3122/jabfm.2018.03.180087

23. Fashner J. Trends in OB care in family medicine residencies: unpublished data available from CAFM Educational Research Alliance (CERA); 2019.

24. Tong ST, Hochheimer CJ, Barr WB, et al. Characteristics of graduating family medicine residents who intend to practice maternity care Fam Med. 2018;50(5):345-352. doi:10.22454/ FamMed.2018.631796
25. Tong ST, Makaroff LA, Xierali IM, Puffer JC, Newton WP, Bazemore AW. Family physicians in the maternity care workforce: factors influencing declining trends. Matern Child Health J. 2013;17(9):1576-1581. doi:10.1007/s10995012-1159-8

26. Sutter MB, Prasad R, Roberts MB, Magee SR. Teaching maternity care in family medicine residencies: what factors predict graduate continuation of obstetrics? A 2013 CERA program directors study. Fam Med. 2015;47(6):459-465.

27. Dhaliwal H, Roskos S. Changes in maternity care training of Michigan State University Family Medicine Residency Programs after RRC rules changes. Poster Presentation. 2018 Family Centered Maternity Care Conference. Minneapolis, MN.

28. Seehusen DA, Mainous AG III, Chessman AW. Creating a centralized infrastructure to facilitate medical education research. Ann Fam Med. 2018;16(3):257-260. doi:10.1370/afm.2228

29. Magee SR, Eidson-Ton WS, Leeman L, et al Family medicine maternity care call to action: moving toward national standards for training and competency assessment. Fam Med. 2017;49(3):211-217.

30. Hendra R, Hill A. Rethinking response rates: new evidence of little relationship between survey response rates and nonresponse bias. Eval Rev. 2019;43(5):307-330. doi:10.1177/0193841X18807719 